\title{
Article \\ Proper Balance of Small GTPase rab10 Is Critical for PGC Migration in Zebrafish
}

\author{
Chengyu Mo ${ }^{1,2,3}$, Wenjing Li ${ }^{1,2,3}$, Kuntong Jia ${ }^{1,2,3} \mathbb{C}^{-}$, Wei Liu ${ }^{1,2,3, *}$ and Meisheng $\mathrm{Yi}^{1,2,3, *}$ \\ 1 School of Marine Sciences, Sun Yat-sen University, Zhuhai 519082, China; mochy5@mail2.sysu.edu.cn (C.M.); \\ liwj77@mail2.sysu.edu.cn (W.L.); jiakt3@mail.sysu.edu.cn (K.J.) \\ 2 Southern Marine Science and Engineering Guangdong Laboratory, Zhuhai 519082, China \\ 3 Guangdong Provincial Key Laboratory of Marine Resources and Coastal Engineering, \\ Guangzhou 510275, China \\ * Correspondence: liuw68@mail.sysu.edu.cn (W.L.); yimsh@mail.sysu.edu.cn (M.Y.)
}

check for updates

Citation: Mo, C.; Li, W.; Jia, K.; Liu, W.; Yi, M. Proper Balance of Small GTPase rab10 Is Critical for PGC Migration in Zebrafish. Int. J. Mol. Sci. 2021, 22, 11962. https://doi.org/ $10.3390 /$ ijms222111962

Academic Editors: Marco Barchi, Paolo Chieffi and Andrea Garolla

Received: 8 October 2021

Accepted: 2 November 2021

Published: 4 November 2021

Publisher's Note: MDPI stays neutral with regard to jurisdictional claims in published maps and institutional affiliations.

Copyright: (c) 2021 by the authors. Licensee MDPI, Basel, Switzerland. This article is an open access article distributed under the terms and conditions of the Creative Commons Attribution (CC BY) license (https:// creativecommons.org/licenses/by/ $4.0 /)$.

\begin{abstract}
MicroRNAs (miRNAs) play important roles in post-transcriptional repression in nearly every biological process including germ cell development. Previously, we have identified a zebrafish germ plasm-specific miRNA miR-202-5p, which regulates PGC migration through targeting $c d c 42 s e 1$ to protect $c d c 42$ expression. However, knockdown of $c d c 42 s e 1$ could not significantly rescue PGC migration in maternal miR-202 mutant (MmiR-202) embryos, indicating that there are other target genes of $m i R-202-5 p$ required for the regulation of PGC migration. Herein, we revealed the transcriptional profiles of wild type and MmiR-202 PGCs and obtained 129 differentially expressed genes (DEGs), of which 42 DEGs were enriched cell migration-related signaling pathways. From these DEGs, we identified two novel miR-202-5p target genes $p r d m 12 b$ and rab10. Furthermore, we found that disruption of rab10 expression led to significantly migratory defects of PGC by overexpression of rab10 siRNA, or WT, inactive as well as active forms of rab10 mRNA, and WT rab10 overexpression mediated migratory defects could be partially but significantly rescued by overexpression of $m i R-202-5 p$, demonstrating that rab10 is an important factor involved miR-202-5p mediated regulation of PGC migration. Taken together, the present results provide significant information for understanding the molecular mechanism by which miR-202-5p regulates PGC migration in zebrafish.
\end{abstract}

Keywords: primordial germ cells; miR-202-5p; rab10; migration

\section{Introduction}

Primordial germ cells (PGCs), the progenitors of gametes, segregate at early stages of embryonic development $[1,2]$. Shortly after specification, PGCs become motile and migrate towards the genital ridge where PGCs with somatic gonadal precursors form the gonad and enter gametogenesis to produce sperms or eggs [3-7]. In lower animals such as fruit fly, frog and zebrafish, the specification of PGC is determined by maternal germ plasm, a phaseseparated liquid structure containing many specific factors such as coding mRNAs and their proteins (dnd, vasa and nanos) [8-10], long non-coding RNAs (pgc and $x l s i r t)$ [11-13], piRNAs [14], as well as microRNAs (miR-9c, miR-969 and $m i R-202-5 p)$ [15-17]. These germ plasm components play critical roles in asymmetric assembly of germ plasm, transcriptional repression, germ cell survival and direction of germ cell migration [1,18-20].

Like Dictyostelium discoideum or Entamoeba histolytica, zebrafish PGC migration utilizes the term of bleb, which is driven by hydrostatic pressure and cytoplasmic flow to emerge cells detaching from the actin cortex and forming a round protrusion in the cell front [21]. PGC migration requires high contractility, flexible protrusion formation and reduced adhesion levels. Firstly, the onset of PGC migration coincides with a decreased level of E-cadherin controlled by the regulator of G-protein signaling 14a protein [22]. Then, the morphology and motility of PGCs is maintained by three molecular modules including myosin light chain kinase (Mlck), Zeb1 and A5b, through elevating the cell contractility, 
decreasing the level of E-cadherin and reducing the level of membrane cortex attachment, respectively [23]. The Cxcl12a chemokine gradient is critical for directing PGC migration towards the genital ridge [24]. During PGC migration, the cell front is established by high $\mathrm{pH}$, which needs the function of ca15b and filopodia [25], and an elevation in Rac1 activity to enhance actin filament assembly [26]. In addition, the members of GTPases superfamily $\mathrm{ROCK} / \mathrm{Rac} / \mathrm{Cdc} 42$ participate in the regulation of membrane invaginations, which is critical for pseudopod extension of zebrafish PGC $[27,28]$. The Reduction in the levels of cdc42 expression or cdc42 activity leads to migratory defects in zebrafish PGC [15,27]. Therefore, the regulation of PGC migration is a complex biological progress.

MicroRNAs (miRNAs) are a kind of endogenous 18-25 nt non-coding RNAs, which pair with the mRNA of protein-coding genes to achieve post-transcriptional regulation in almost all biological processes including germ cell development [29-32]. let-7, the first identified miRNA in animals, is a critical factor in the determination of germ versus somatic cell fates in mammals [33-36]. miR-430 plays an important role in the clearance of maternal mRNAs during maternal to zygotic transition [37]. The miR-430 regulation of Cxcl12 chemokine signaling confers genetic robustness in directing PGC migration towards the genital ridge [38]. Another miRNA $m i R-202-5 p$ has been reported as a gonad-specific miRNA in zebrafish [39], Atlantic salmon [40], and medaka [41]. In zebrafish, miR-202-5p is a component of maternal germ plasm [16]. Loss of miR-202-5p results in an elevation in the level of cdc42se1, which decreases the expression of cdc42, ultimately, leading to severe migratory defects in PGCs [15]. However, knockdown of $c d c 42 s e 1$ can't effectively rescue PGC migration in maternal miR-202 mutant (MmiR-202) embryos, suggesting that there might exist other miR-202-5p target genes contributing to the regulation of PGC migration through different signaling networks.

To further understand the molecular mechanism underlying miR-202-5p mediated regulation of PGC migration, we analyzed the transcriptional files of wild type (WT) and MmiR-202 PGCs by transcriptome sequencing. The transcriptome data revealed 129 differentially expressed genes (DEGs), which were widely distributed in cell migration related to signaling pathways such as extracellular matrix, cell polarity, cytoskeleton, cell adhesion, cell motility and small GTPase activity. From these DEGs, we identified two novel miR-202-5p target genes prdm12b and rab10. Furthermore, loss- and gain-of-function experiments indicated that the proper balance of rab10 was critical for PGC migration.

\section{Results}

\subsection{Transcriptional Profiles in WT and MmiR-202 PGCS}

Previously, we have generated a maternal miR-202-5p mutant (MmiR-202) zebrafish line [15]. In this study, the PGCs were visualized by injection of $g f p$-nanos $3^{\prime} u t r$ mRNA in 1-cell embryos, and the GFP-labelled PGCs of WT or MmiR-202 embryos were isolated by fluorescence-activated cell sorting (FACS) at $24 \mathrm{~h}$ post fertilization (hpf). The collected PGCs were divided into three groups of WT and MmiR-202 PGC groups (300 PGCs each group) to construct six sequencing libraries. By Illumina sequencing, we obtained $546 \mathrm{M}$ clean reads with about $91 \mathrm{M}$ clean reads in each library, $89.2 \%$ of which were mapped to the zebrafish genome and annotated as 30,878 transcripts (Table 1).

Table 1. The quality information of transcriptome sequencing.

\begin{tabular}{cccccc}
\hline Sample & $\begin{array}{c}\text { Raw } \\
\text { Reads }\end{array}$ & Clean Reads & $\begin{array}{c}\text { Clean Reads } \\
\text { Rate (\%) }\end{array}$ & Q30 (\%) & $\begin{array}{c}\text { Mapping Rate } \\
(\%)\end{array}$ \\
\hline WT PGC1 & $92,981,332$ & $90,378,978$ & 97.20 & 92.49 & 89.66 \\
WT PGC2 & $94,130,668$ & $91,742,980$ & 97.46 & 92.99 & 90.48 \\
WT PGC3 & $93,087,162$ & $91,203,598$ & 97.98 & 93.34 & 88.52 \\
MmiR-202 PGC1 & $94,567,190$ & $91,905,698$ & 97.19 & 93.48 & 88.70 \\
MmiR-202 PGC2 & $95,092,164$ & $91,571,918$ & 96.30 & 93.25 & 88.75 \\
MmiR-202 PGC3 & $95,230,438$ & $92,724,062$ & 97.37 & 93.26 & 88.91 \\
\hline
\end{tabular}


The expression level was calculated using FPKM (fragments per kilobase million mapped reads). To yield reliable results, only genes with FPKM $\geq 1$ in at least three samples were subjected to analyze differentially expressed genes (DEGs). We obtained 129 DEGs including 46 up-regulated and 83 down-regulated DEGs in MmiR-202 PGCs compared to WT PGCs (Figure 1A,B). These DEGs were distributed in 39 GO terms and were mostly enriched in cell part, cellular process, biological regulation and binding (Figure 1C). In summary, we established the transcriptional files of WT and MmiR-202 PGCs.
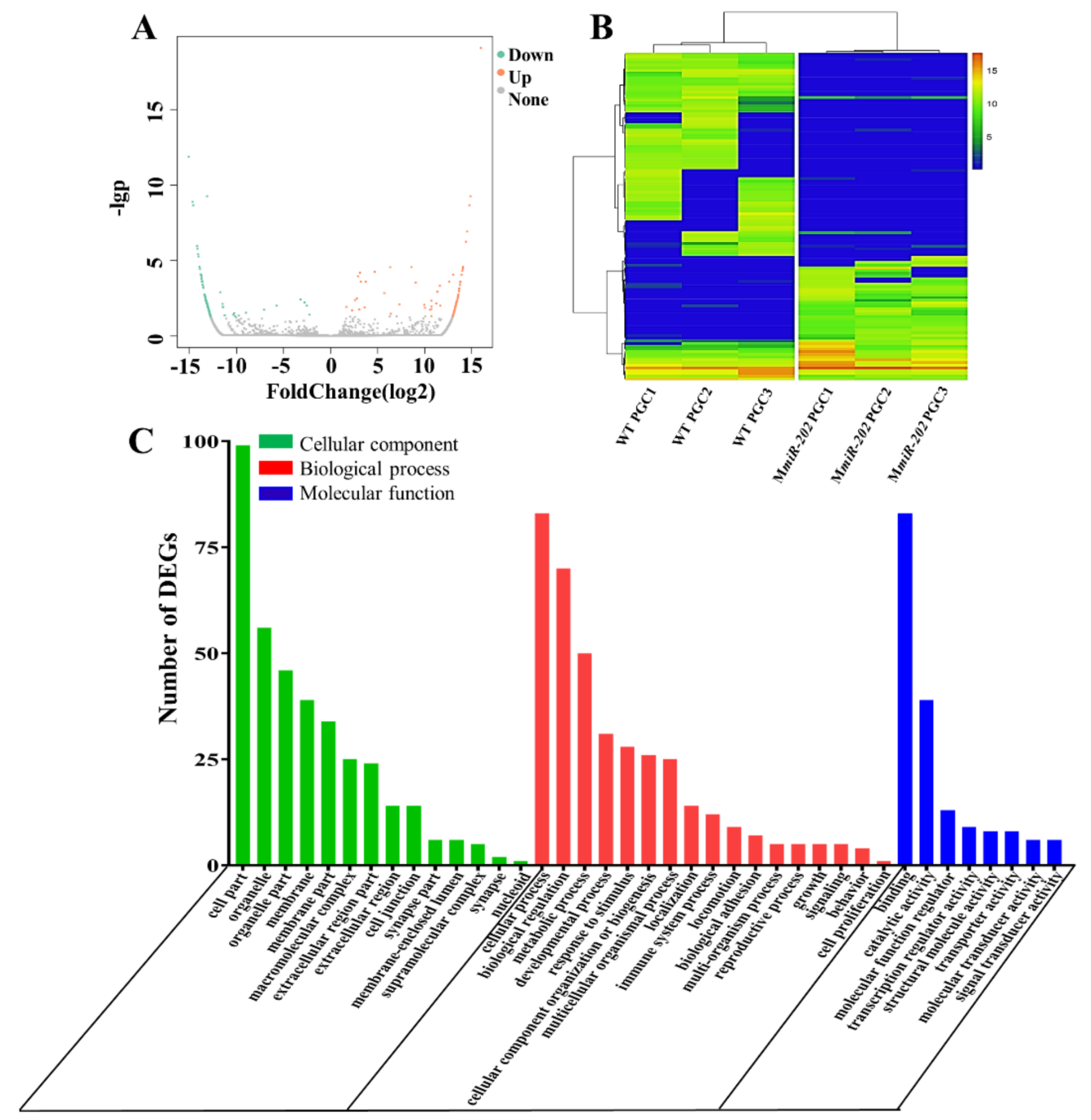

Figure 1. The expression pattern and GO annotation of DEGs. (A) Volcano plot of DEGs in WT and MmiR-202 PGCs. The up-regulated and down-regulated DEGs were respectively shown as red and green dots. (B) Heatmap for the cluster analysis of DEGs in WT and MmiR-202 PGCs. (C) The Gene Ontology annotation of all DEGs. The X-axis represents the 39 subcategories. The Y-axis shows the number of DEGs.

\subsection{Analysis of the DEGs Associated with PGC Migration}

To explore genes involved in miR-202-5p mediated PGC migration, we performed bioinformatic analysis to predict functions of these DEGs and found that 42 DEGs were enriched in cell migration associated biological processes including extracellular matrix, cell polarity, cytoskeleton, cell adhesion, cell motility and small GTPase activity (Table 2, Figure 2A). Among these DEGs, eight DEGs were involved in the regulation of GTPase activity, a process essential for the regulation of PGC polarity [27]; seven DEGs were associated with the regulation of cadherin binding, and proper regulation of cadherin was required for the onset of PGC migration [42]. In addition, there were seven DEGs 
participating in assembly of myosin such as $m y l 7, t p m 4 b$, rab36 and $c m l c 1$, bleb formation panx $1 a$ as well as two positive regulator associated cell motility cavin1a and rab36, and the transcriptome data indicated that their expression levels were down-regulated in MmiR-202 PGCs compared to WT PGCs.

Table 2. The DEGs associated with GO terms of migratory events.

\begin{tabular}{|c|c|}
\hline $\begin{array}{c}\text { GO Terms Related } \\
\text { to Migratory } \\
\text { Events }\end{array}$ & DEGs \\
\hline Bleb & panx1a \\
\hline Cell polarity & $f g f 13 b$ \\
\hline Cell motility & rab36, cavin1a \\
\hline Chemokine & chia.4, ccl20a.3 \\
\hline Cadherin & cdh18a, clstn3, cblc, si:dkey-81e3.2, ppl, prx, dock9b \\
\hline Cell adhesion & cldne, col28a2a, cdh18a, clstn3, hyal1, spon1a, si:dkey-81e3.2, itga9, styk1b \\
\hline Cytoskeleton & $\begin{array}{c}\text { al935300.3, actc1a, anxa1c, epha4b, mcf2a, ppl, prx, ttn.2, tpm4b, synpo2lb, } \\
\text { si:dkey-81e3.2, si:dkey-26g8.5, zgc:86896, zgc:174153 }\end{array}$ \\
\hline $\begin{array}{l}\text { Extracellular } \\
\text { matrix }\end{array}$ & col1a1a, col1a2, col28a2a, fgf13b, vit, ndnfl, tns2b, itga9, si:dkey-81e3.2, megf6a \\
\hline GTPase activity & dock $9 b$, epha4b, mcf2a, nudt1, rap1gap $2 b$, rab10, rab36, snx18b \\
\hline Myosin & myl7, rab36, cmlc1, tpm4b \\
\hline
\end{tabular}

A

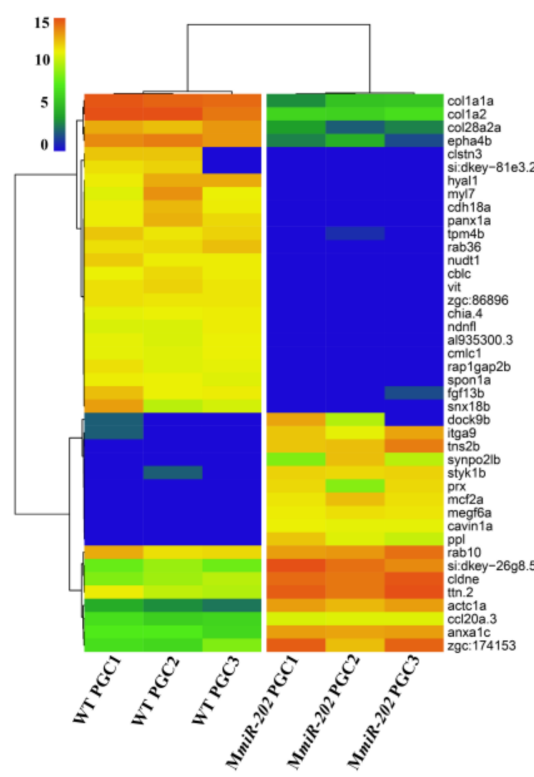

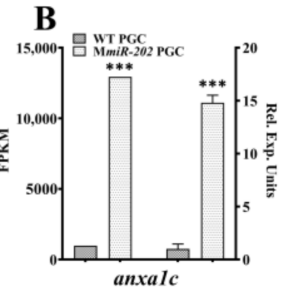
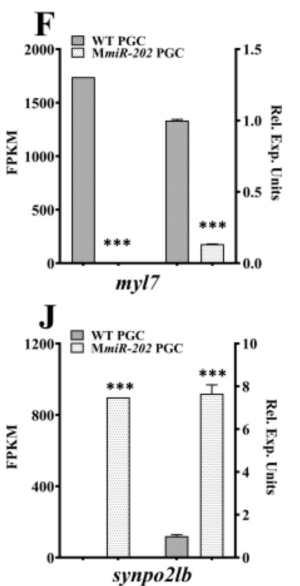
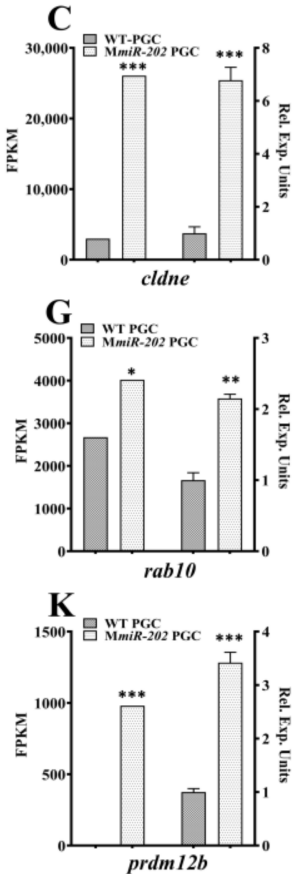
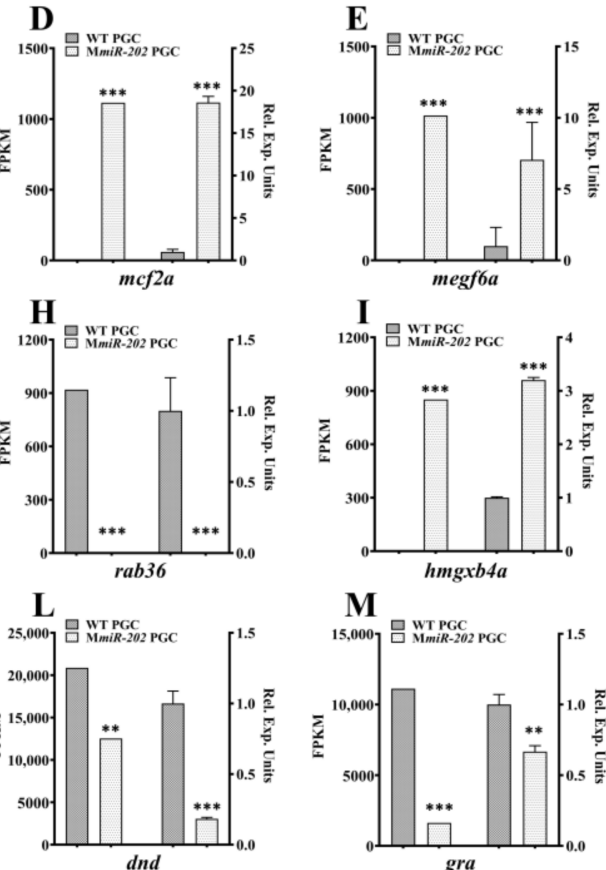
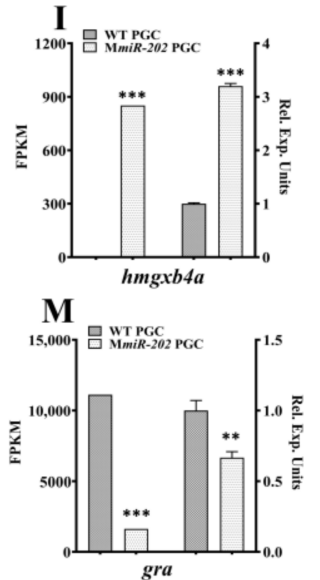

Figure 2. Heatmap of representative DEGs related to cell migration and verification of the expression patterns by qPCR analysis. (A) Two-dimensional hierarchical cluster of DEGs associated with cell migration. (B-M) Validation of the transcriptome by qRT-PCR analysis of representative genes including (B) anxa1c, (C) cldne, (D) mcf2a, (E) megf6a, (F) myl7, (G) rab10, (H) rab36, (I) hmgxb4a, (J) synpo2lb, (K) prdm12b, (L) dnd and (M) gra. The FPKM values (left) and the relative expression levels of qPCR (right) are shown. (B-G) The results were representative of more than three independent experiments in triplicate. Three reference genes ef1a, $\beta$-actin and rpl13a were used in every PCR examination to normalize gene expression levels with $2^{-\Delta \Delta \mathrm{Ct}}$ method. The statistics were calculated and analyzed by Student's $t$-test, ${ }^{*} p<0.05$; ${ }^{* *} p<0.01 ;{ }^{* * *} p<0.001$.

To validate the reliability of transcriptome data, we performed qPCR analysis of 12 representative DEGs including two PGC marker genes $d$ nd and gra, four DEGs with over 10-fold change such ashmgxb4a, prdm12b and myl7, an ECM-related DEG megf6a, 
two cytoskeleton-related DEGs anxa1c and synpo2lb, three GTPase-related DEGs rab10, $m c f 2 a$ and $r a b 36$, as well as cell adhesion-related DEG cldne. qPCR results exhibited a high consistency with the transcriptome data (Figure 2B-M): the transcriptional levels of $d n d, g r a$, $m y l 7$ and rab36 were significantly downregulated, whereas $h m g x b 4 a, p r d m 12 b, m e g f 6 a, r a b 10$, $m c f 2 a$, anxa1c and synpo2lb were significantly up-regulated in MmiR-202 PGCs compared to WT PGCs. Hence, the transcriptome data demonstrated that maternal loss of $m i R-202-5 p$ led to dysregulation of multiple PGC migration-related signaling pathways.

\section{3. rab10 and prdm12b Are Novel miR-202-5p Target Genes}

To identify novel miR-202-5p target genes associated with PGC migration, we screened whether the $3^{\prime}$ untranslated region (UTR) of any DEG contained miR-202-5p binding sites by bioinformatic analysis. We found that the $3^{\prime} \mathrm{UTR}$ of $r a b 10$ and $p r d m 12 b$ contained the canonical seed sequences of $m i R-202-5 p$ (Figure 3A,B). Next, we employed luciferase and RNA reporter systems to clarify whether $r a b 10$ and $p r d m 12 b$ are subjected to $m i R-202-5 p$ regulation. Firstly, we constructed recombinant psiCheck2 plasmids by linking WT or mutant $3^{\prime} \mathrm{UTR}$ of rab10 or prdm12b to the open reading frame (ORF) of luciferase and transiently transfected them to HEK293T cells. Dual luciferases assay indicated that the relative activity of luciferase fusing WT $3^{\prime}$ UTR of $p r d m 12 b$ or rab10 was significantly decreased in miR-202-5p mimics transfected HEK293T cells, whereas mutation of $m i R-202-5 p$ binding sites significantly attenuated the repression (Figure 3C). Secondly, we employed an RNA reporter by linking the ORF of red fluorescent protein (RFP) with WT or mutant 3'UTR of rab10 or prdm $12 b$ and co-injected it with miR-202-5p mimics or control mimics into 1-cell embryos. Quantitative pixel-intensity analysis revealed a significant decrease of RFP in the presence of miR-202-5p mimics, whereas the decrease was abolished by the mutation of $m i R-202-5 p$ binding sites (Figure 3E,F). Thus, as previously shown for $c d c 42 s e 1$ and trim $25[15,43]$, the $3^{\prime}$ UTRs of rab10 or prdm12b were responsible for conferring negative regulation on the translation of linked ORFs through the action of miR-202-5p. Consistently, qPCR analysis of the RNA extracted from $m i R-202-5 p$ or control mimic-injected embryos revealed a significant decrease of endogenous rab10 or $p r d m 12 b$ in $m i R-202-5 p$ mimic-injected embryos (Figure 3D), meanwhile there was a significant elevation of rab10 or prdm $12 b$ in MmiR-202 PGCs (Figure 2G,K). These data indicated that rab10 or $p r d m 12 b$ are $m i R-202-5 p$ target genes.

\subsection{The Balance of rab10 Is Critical of PGC Migration}

To investigate the possible roles of rab10 and prdm12b in zebrafish PGC development, we employed loss- and gain-of-function by injection of corresponding siRNA and mRNA, respectively. Firstly, qPCR analysis on the extracted RNA from control or rab10 siRNA injected embryos revealed a significant reduction in levels of rab10 in rab10 siRNA injected embryos, and the reduction relied on the dosages of rab10 siRNA (Figure 4A). Secondly, we employed the fluorescence reporter of rab10-rfp mRNA and co-injected it with control or rab10 siRNA into 1-cell embryos. Quantitative pixel-intensity analysis revealed a significant decrease in the levels of RFP in rab10 siRNA injected embryos compared to that in control siRNA injected embryos (Figure 4B,C). These results demonstrated that rab10 siRNA is efficient to decrease endogenous rab10 expression in vivo.

Next, we investigated whether knockdown of rab10 affected PGC migration in the PGC fluorescence labeling transgenic line (kop: egfp-UTR-nos3). We observed a significant mislocalization of PGCs in rab10 siRNA injected embryos at 24 hpf (Figure 4D-G). We observed that the proportion of embryos with mislocalized PGCs and average number of mislocalized PGCs was 29.27\% and 5.1, 34.88\% and 6.4, 45.72\% and 7.3 in 50, 150 and 300 pg rab10 siRNA injected embryos, respectively (Figure 4N,O). Because the expression of rab10 was elevated in MmiR-202 PGC, we speculated that overexpression of rab10 also affected PGC migration. To verify it, ectopic overexpression of rab10 was performed by injection of WT rab10 mRNA. We observed that ectopic overexpression of rab10 led to a significantly migratory defect of PGCs. The proportion of embryos with mislocalized PGCs and average 
number of mislocalized PGCs in 50, 100 and 200 pg rab10 mRNA was $37.0 \%$ and 6.5, 46.4\% and $7.5,59.5 \%$ and 8.6, respectively (Figure $4 \mathrm{H}-\mathrm{K}, \mathrm{N}, \mathrm{O}$ ). Therefore, the migratory defect of PGC exhibited a significant dosage effect associated with the injected dosage of either rab10 siRNA or mRNA. Rab proteins alternate between GTP- and GDP-bound states, which functions as the molecular switch in regulation of cell trafficking and movement [44]. It has been reported that canine rab10 mutants rab10T23N and rab10Q68L prefer to maintain inactive GDP- and active GTP-bound state, respectively [45]. Homological comparison indicated that the two functional sites were conserved in zebrafish rab10 proteins. We constructed inactive and active mRNA mutants of rab10T23N and rab10Q68L and then injected them in 1-cell embryos, respectively. We observed that injection of either rab10T23N or rab10Q68L mRNA resulted in migratory defects in PGCs (Figure 4L,M).

A

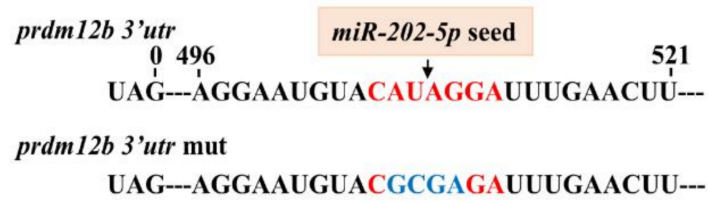

B

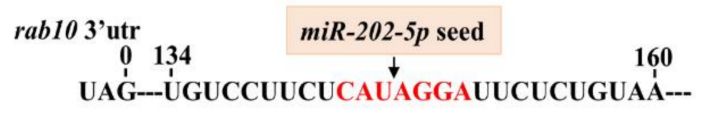

rab10 3'utr mut

UAG---UGUCCUUCUCGCGAGAUUCUCUGUAA---
C

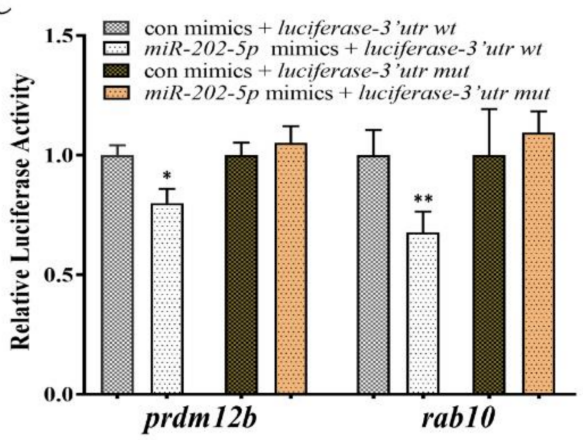

E

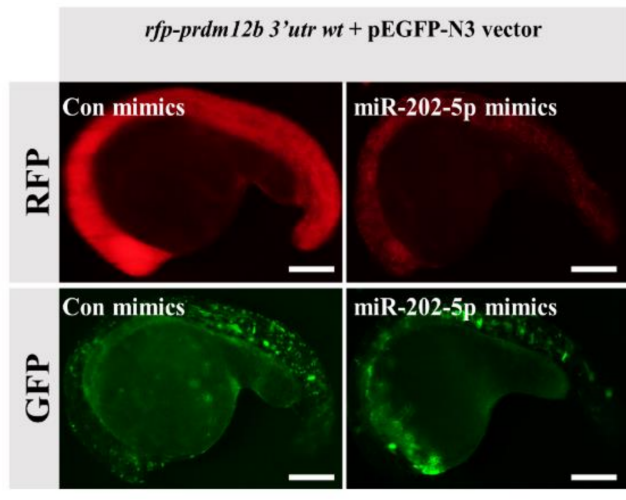

D

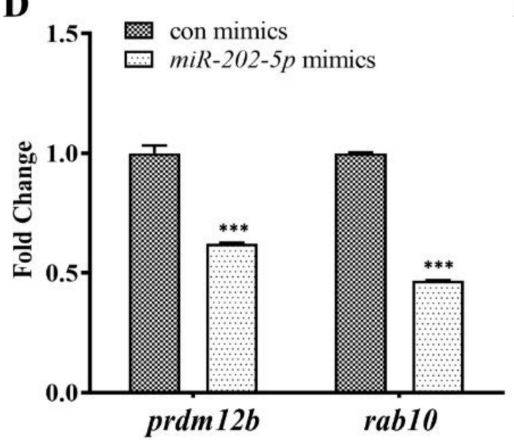

F

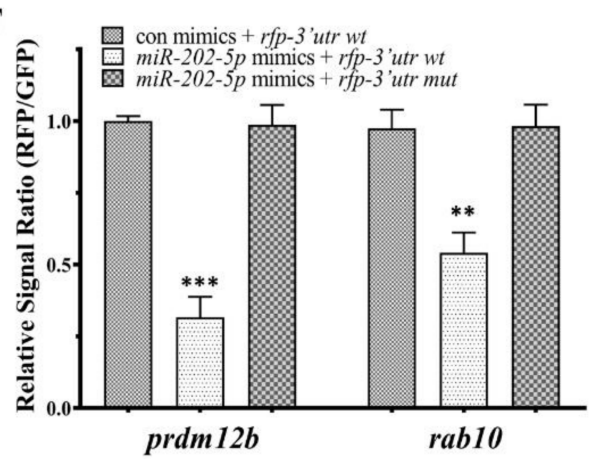

Figure 3. $m i R-202-5 p$ directly regulates $p r d m 12 b$ and $r a b 10$. (A,B) The sequence information of the $3^{\prime}$ utr of $p r d m 12 b$ and $r a b 10$. The canonical $m i R-202-5 p$ binding sites and its mutant were shown in red and blue, respectively. (C) Relative luciferase activity in HEK293T cells transfected with psiCHECK2-3'utr wt (prdm12b or rab10) or psiCHECK2-3'utr mut (prdm12b or rab10) in the presence of control mimics (con mimics) or miR-202-5p mimics. (D) qRT-PCR analysis of $p r d m 12 b$ and $r a b 10$ mRNA in 24hpf embryos injected with control or miR-202-5p mimics. (E) The representative images of embryos co-injected with mRNAs of $r f p$-prdm12b 3'utr wt, rfp-prdm12b 3'utr mut, rfp-rab10 3'utr wt or rfp-rab10 3'utr mut in the presence of control or miR-202-5p mimics. All embryos were co-injected with pEGFP-N3 vector as a control. (F) The relative signal ratio of RFP/GFP in the experiment presented in (E). $(\mathbf{C}, \mathbf{D}, \mathbf{F})$ The results were representative of more than three independent experiments in triplicate. $\beta$-actin was used as an internal control to normalize gene expression levels with $2^{-\Delta \Delta \mathrm{Ct}}$ method ${ }^{*} p<0.05 ;{ }^{* *} p<0.01 ;{ }^{* * *} p<0.001$. 

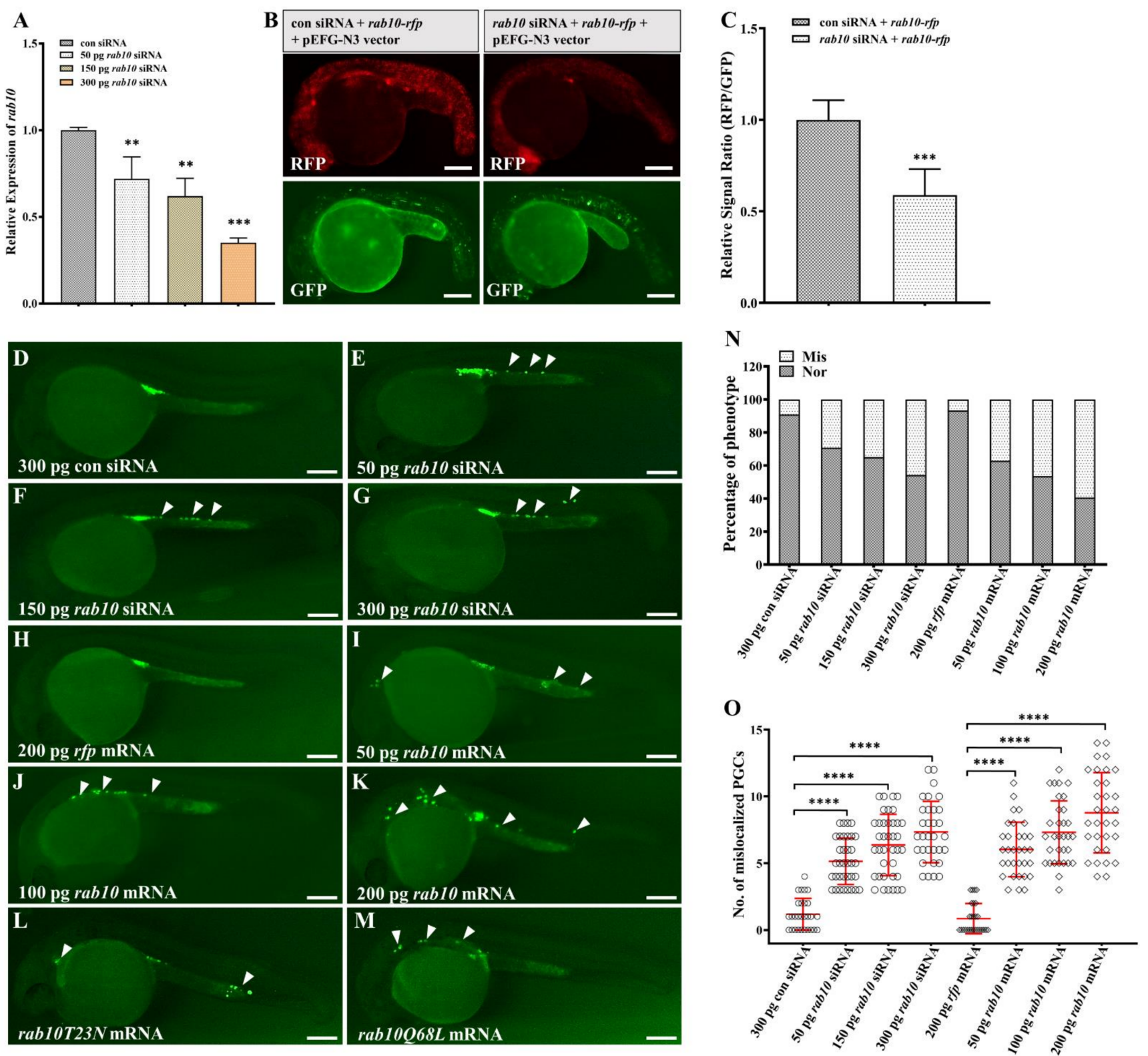

Figure 4. Disruption of rab10 balance leads to PGC mislocalization. (A) qRT-PCR analysis of rab10 mRNA in 24hpf embryos injected with control siRNA (con siRNA) or gradient rab10 siRNA (50, 150, 300 pg). (B) Co-injection of rab10 siRNA decreased expression of RFP in embryos injected with rab10-rfp mRNA compared to embryos co-injected with control siRNA. All embryos were co-injected with pEGFP-N3 vector as a control. (C) Quantitative representation of the normalized signal intensity in the experiment presented in (B). (D-M) Representative images of embryos injected with 300 pg con siRNA (D), 50 pg rab10 siRNA (E), 150 pg rab10 siRNA (F), 300 pg rab10 siRNA (G), 200 pg rfp mRNA (H), 50 pg rab10 mRNA (I), 100 pg rab10 mRNA (J), 200 pg rab10 mRNA (K), rab10T23N mRNA (L), and rab10Q68L mRNA (M). Arrowheads indicate mislocalized PGCs. (N) The percentage of PGC phenotypes in embryos with (D-K). (O) The number of mislocalized PGCs in each embryo with the experiment presented in (D-K). The average number of mislocalized PGCs were showed in red line by mean $\pm \mathrm{sd}$. $(\mathbf{A}, \mathbf{C}, \mathbf{N}, \mathbf{O})$ The results were representative of more than three independent experiments in triplicate. $\beta$-actin was used as an internal control to normalize gene expression levels with $2^{-\Delta \Delta \mathrm{Ct}}$ method. ${ }^{* *} p<0.01$; $^{* * *} p<0.001$, **** $p<0.0001$. Scale bar, $100 \mu \mathrm{m}$.

Furthermore, PGC-specific overexpression of rab10 by injection of rab10-rfp-utr-nos3 mRNA into 8-cell embryos led to a significant PGC mislocalization (Figure 5A-C). In summary, the proper balance of rab10 ensures PGC migration in zebrafish. 

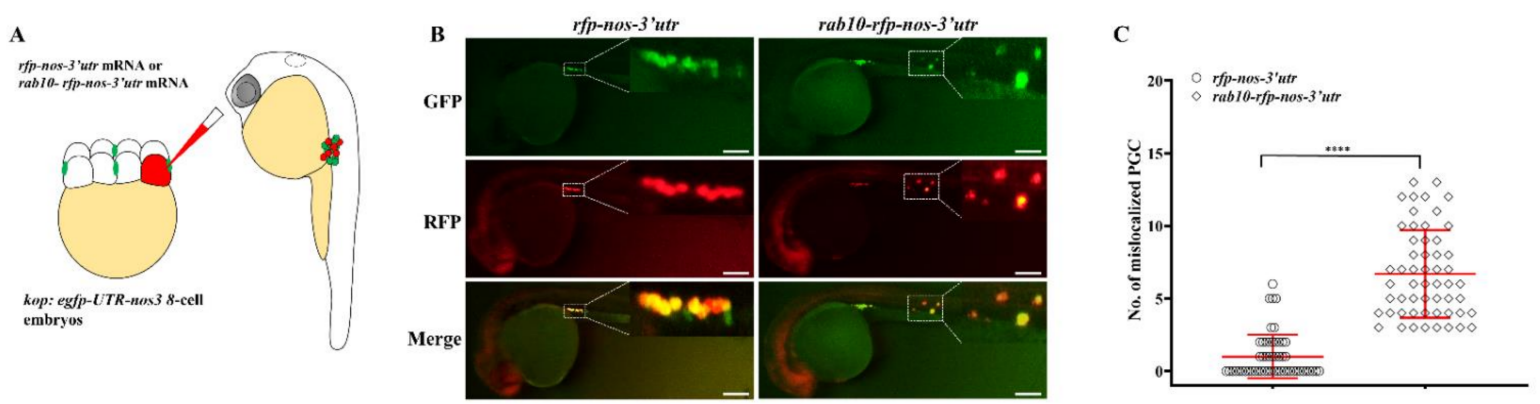

Figure 5. PGC-specific overexpression of rab10 leads to PGC mislocalization. (A) rab10-rfp-nos-3'utr mRNA was injected into 8-cell embryos of kop: egfp-UTR-nos3 lines. (B) Representative images of PGCs in embryos injected with $r f p$-nos mRNA or rab10-rfp-nos-3' $3^{\prime}$ tr at prim 5 stage. (C) The number of mislocalized PGCs in each embryo injected with $r f p$-nos mRNA or rab10-rfp-nos-3'utr at prim 5 stage. (C) The results were representative of more than three independent experiments in triplicate. The average number of mislocalized PGCs were showed in red line by mean \pm sd. ${ }^{* * *} p<0.0001$. Scale bar, $100 \mu \mathrm{m}$.

\section{5. miR-202-5p Negatively Regulates rab10 in PGC Migration}

To clarify the regulatory relationship between miR-202-5p and rab10 during PGC migration, we injected rab10 siRNA or miR-202-5p mimics to rescue the migratory defect of PGCs in embryos injected WT rab10 mRNA. Compared to WT rab10 mRNA injected embryos, co-injection of rab10 mRNA with either rab10 siRNA or miR-202-5p mimics could significantly reduce both the proportion of embryos with mislocalized PGCs and average number of mislocalized PGCs (Figure 6), although some embryos still had a modest number of mislocalized PGCs. Therefore, overexpression of miR-202-5 $p$ could partially rescue PGC migratory defects caused by overexpression of rab10.

\subsection{Knockdown of rab10 Fails to Rescue PGC Migration in MmiR-202 Embryos}

On the other hand, we investigated whether knockdown of rab10 could rescue the migratory defect in MmiR-202 PGC. Different dosages (50, 150 and $300 \mathrm{pg}$ ) of rab10 siRNA were injected into 1-cell MmiR-202 embryos. In 300 pg control siRNA injected WT embryos, there were $6.21 \%$ embryos with an average number (0.91) of mislocalized PGC (Figure 7A). On the other hand, the proportion of embryos with mislocalized PGCs and average number of mislocalized PGCs was $30.56 \%$ and 4.76 in control siRNA injected MmiR-202 embryos (Figure 7B). However, the proportion of embryos with mislocalized PGCs and average number of mislocalized PGCs increased to $36.36 \%$ and $6.22,37.50 \%$ and $6.50,43.59 \%$ and 7.29 in 50, 150 and 300 pg rab10 siRNA injected MmiR-202 embryos, respectively (Figure 7C-E,G,H). Therefore, knockdown of rab10 in MmiR-202 embryos resulted in a severer defect in PGC migration compared to MmiR-202 embryos. Previously, we have found that $m i R-202-5 p$ protects PGC migration by targeting and repressing the expression of $c d c 42 s e 1$ [15]. Therefore, we attempted to rescue PGC migration in MmiR-202 embryos by double knockdown of rab10 and cdc42se1. However, we observed that the proportion of embryos with mislocalized PGCs and average number of mislocalized PGCs further increased to $45.71 \%$ and 7.34 in $300 \mathrm{pg}$ rab10 siRNA and $4000 \mathrm{pg} c d c 42 s e 1 \mathrm{MO}$ co-injected MmiR-202 embryos, demonstrating that double knockdown of rab10 and $c d c 42 s e 1$ led to a stronger migratory defect in the PGC migration of MmiR-202 embryos (Figure 7F-H). Therefore, the migratory defect caused by maternal loss of miR-202-5p was complex. 

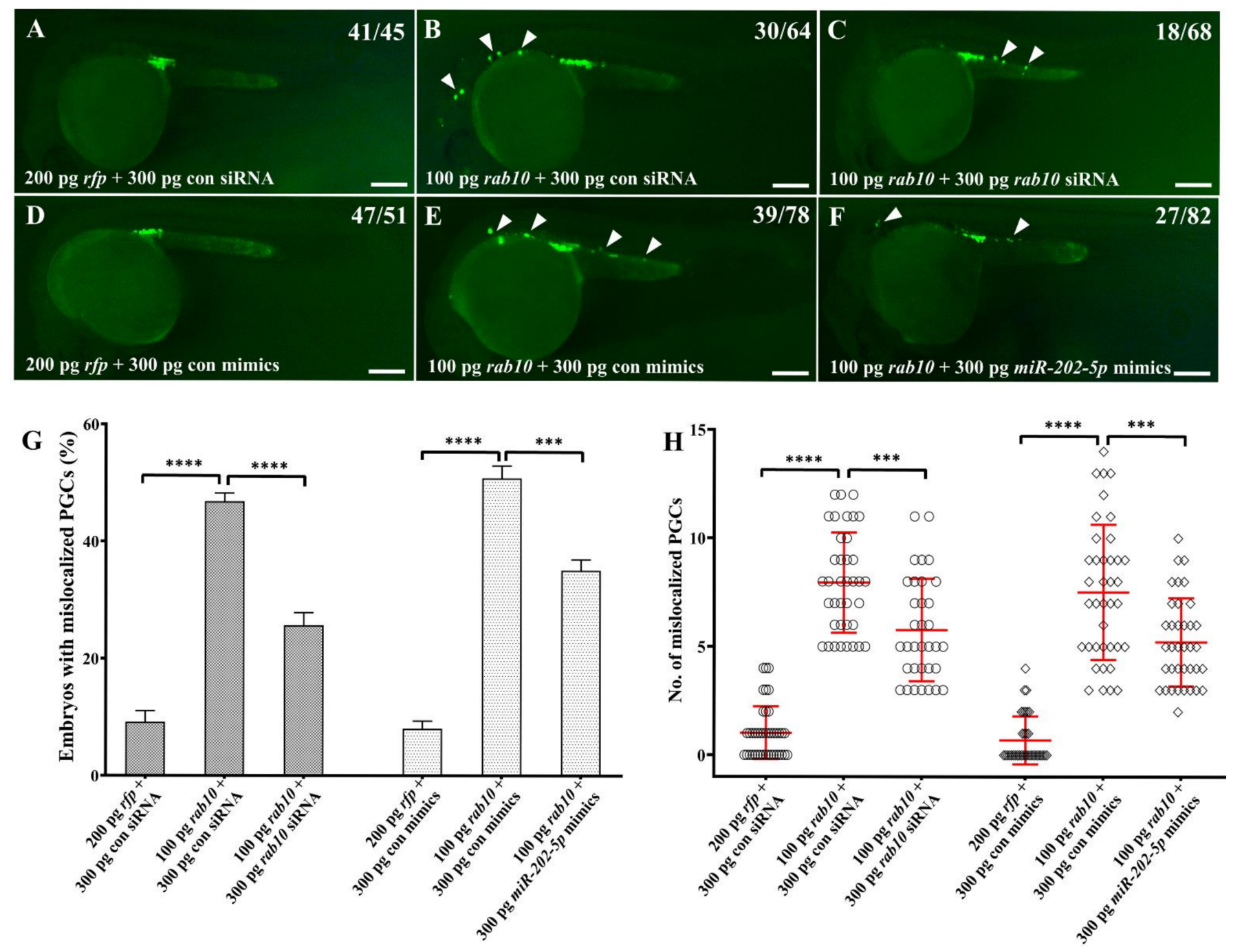

Figure 6. Overexpression of $m i R-202-5 p$ partially rescues PGC migration in embryos overexpressing rab10. (A-F) Representative images of PGCs in embryos injected with $200 \mathrm{pg} r f p$ mRNA and 300 pg control siRNA or control mimics (A,D), 100 pg rab10 mRNA and 300 pg control siRNA or control mimics (B,E), 100 pg rab10 mRNA and 300 pg rab10 siRNA or miR-202-5p mimics (C,F). Arrowheads indicate mislocalized PGCs. The corresponding phenotypes in different groups of embryos were shown in the upper right of the panels (A-F). (G) The percentage of embryos with mislocalized PGCs in $(\mathbf{A}-\mathbf{F})$. (H) The number of mislocalized PGCs in each embryo in $(\mathbf{A}-\mathbf{F})$. $(\mathbf{G}, \mathbf{H})$ The results were representative of more than three independent experiments in triplicate. The average number of mislocalized PGCs were showed in red line by mean \pm sd. ${ }^{* * *} p<0.001,{ }^{* * * *} p<0.0001$. Scale bar, $100 \mu \mathrm{m}$. 

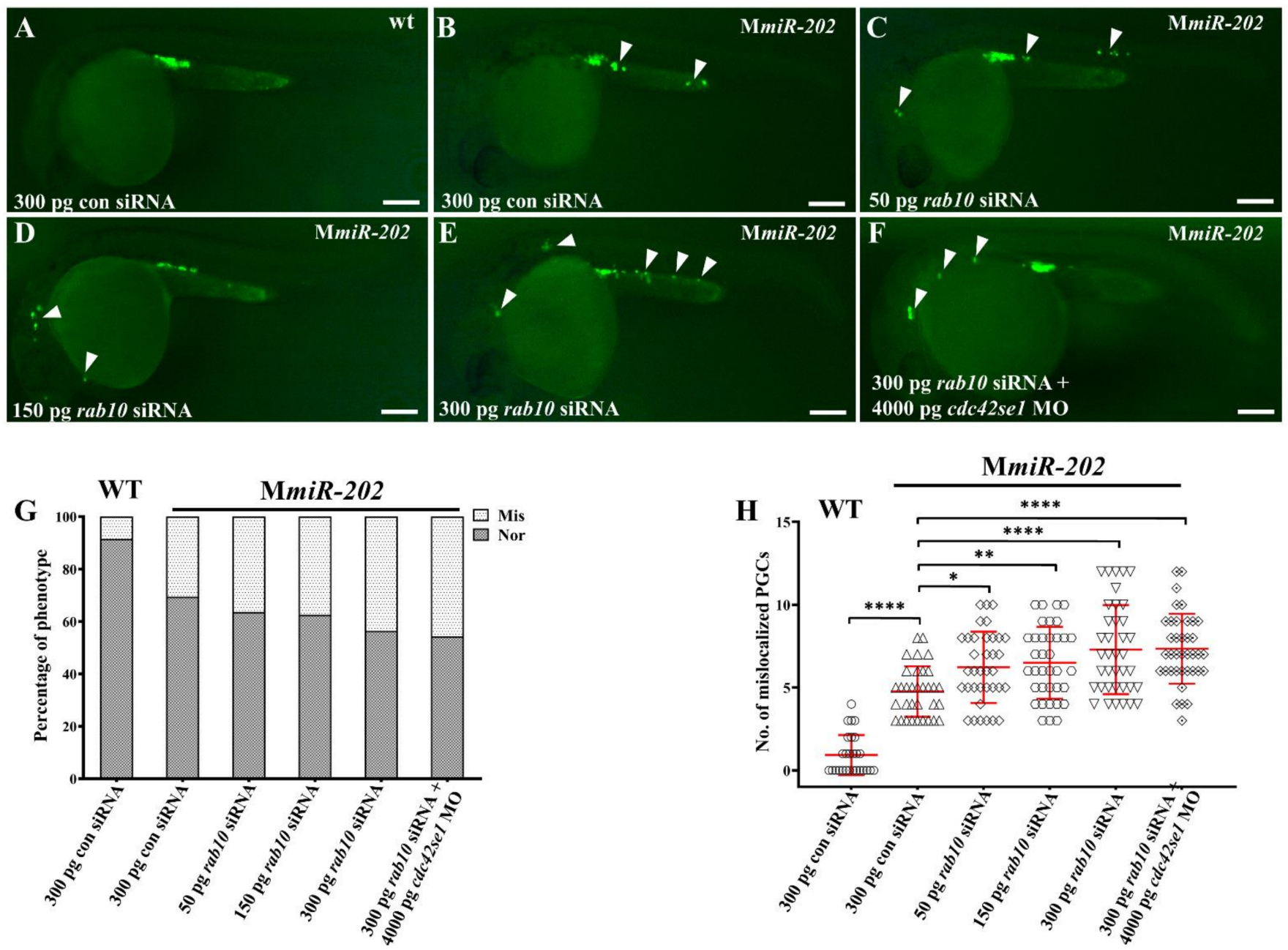

Figure 7. rab10 siRNA and $c d c 42 s e 1$ MO failed to rescue mislocalized PGCs in embryos caused by maternal absence of miR-202-5p. (A) Representative images of PGCs in WT embryos injected with 300 pg con siRNA; (A) Representative images of PGCs in Mmir-202 embryos injected with 300 pg con siRNA (B), 50 pg rab10 siRNA (C), 150 pg rab10 siRNA (D), 300 pg rab10 siRNA (E), and 300 pg rab10 siRNA + 4000 pg cdc42se1 MO (E). Arrowheads indicate mislocalized PGCs. (G) The percentage of embryos with mislocalized PGCs with (A-F). The genotypes of the embryos were shown upper right in each panel. (H) The number of mislocalized PGCs in each embryo in the experiment presented in (A-F). (G,H) The results were representative of more than three independent experiments in triplicate. The average number of mislocalized PGCs were showed in red line by mean $\pm \mathrm{sd} .{ }^{*} p<0.05,{ }^{* *} p<0.01,{ }^{* * * *} p<0.0001$. Scale bar, $100 \mu \mathrm{m}$.

\section{Discussion}

$m i R-202-5 p$ is a conserved in animals, which plays an important role in reproduction [41], gametogenesis [46,47], immunology [43], tumorigenesis [48,49], and cell migration $[15,50,51]$. In mammals, $m i R-202$ is specific to Sertoli cell and might play an important role in the interaction between germ cell and Sertoli cell during spermatogenesis [46,52]. In frog, $m i R-202-5 p$ is a germline-enriched miRNA in early stage of oogenesis [53]. Chicken $m i R-202-5 p$ is highly expressed in spermatogonia rather than PGCs and might regulate germ cell development by targeting LIMK2 [47]. The expression patterns of miR-202-5p are divergent among fish species. In Japanese medaka (Oryzias latipes), miR-202-5p is co-localized with sox 9 in primordial follicles. Loss of $m i R-202$ impairs early folliculogenesis, decreases the number of mature follicles and leads to a dramatic reduction in female fecundity [41]. In zebrafish, $m i R-202-5 p$ is a component of germ plasm. Loss of $m i R-202$ seems to not affect zebrafish fertility but results in a significant defect in PGC migration [16]. Previously, we have revealed a mechanism by which miR-202-5p uses to regulate PGC migration. $m i R-202-5 p$ negatively regulates $c d c 42 s e 1$ to ensure the proper expression of cdc42 
in PGCs. However, it remains vague whether there are other mechanisms for $m i R-202-5 p$ regulating PGC migration by other target genes. In this study, we performed transcriptome sequencing of WT and MmiR-202 PGCs and obtained 146 DEGs. Furthermore, we found that $r a b 10$ acts as a downstream target gene of $m i R-202-5 p$ and plays an important role in PGC migration. Therefore, we revealed a novel mechanism underlying $m i R-202-5 p$ regulation of PGC migration.

Zebrafish PGC forms at about $4 \mathrm{hpf}$, initiates migration at $4.5 \mathrm{hpf}$ and reaches the genital ridge at $24 \mathrm{hpf}[54,55]$. It is better to collect PGCs during the whole migratory process (4-24 hpf) to analyze the dynamic gene expression change in WT and MmiR202 PGCs. However, because of lacking the PGC-specific transgenic miR-202-/- line, it is difficult to collect MmiR-202 PGCs from the onset of PGC migration. The $3^{\prime} \mathrm{UTR}$ of nos1, dnd and $t d r d 7$ regulate differential localization between soma and PGCs [8,9,56]. However, in gfp-nanos 3' utr mRNA injected embryos, the PGC-specific fluorescence could be found at the late segmentation period, usually at $24 \mathrm{hpf}$. Therefore, we collected PGCs in gfp-nanos-3'utr mRNA injected WT and MmiR-202 embryos at 24 hpf to ensure the purity of isolated PGCs. The transcriptome results revealed that 42 DEGs in WT and MmiR-202 PGCs were significantly enriched in cell migration-associated biological processes (Table 2). The motility of PGC requires a decrease of cadherin-mediated tight junction and a proper regulation of myosin-based contractility $[3,23,26]$. However, we found a remarkable elevation in the levels of tight junction-associated genes including cldne, itga 9 and $s t y k 1 b$, but a reduction in the levels of myosin, polarity and bleb associated genes including $m y l 7, t p m 4 b$, rab36, cmlc1, panx1a, cavin $1 a, f g f 13 b$ and rab36 in MmiR-202 PGCs compared to WT PGCs. Chemokine-guided signaling pathway is essential for the direction of PGC migrating towards genital ridges [24,38]. We found two chemokineassociated genes chia.4 and ccl20a.3 were differentially expressed in WT and MmiR-202 PGCs, suggesting that maternal loss of miR-202 might disrupt chemokine signaling to affect PGC migration. In addition, many DEGs were enriched in the regulation of cell adhesion, cytoskeleton, ECM and GTPase activity. Together, the transcriptome files of WT and MmiR-202 PGCs provided global and useful data for understanding the potential signaling pathways involved in $m i R-202-5 p$ regulation of PGC migration.

Because miRNAs rarely encode functional protein products, they usually initiate hierarchical biological events by binding to the mRNAs of target genes to direct post-transcriptional repression. Therefore, identifying target genes will be helpful to understand how miR-202-5p regulates PGC migration. From these DEGs, we identified two novel miR-202-5p target genes prdm12 and rab10. The members of PR domain-containing (PRDM) family are critical in regulation of DNA methylation and stem cell population maintenance. PRDM1 and PRDM14 are critical determinants of mammalian germ cell lineages from embryonic cells [57,58]. However, zebrafish PRDM family mainly regulate craniofacial development [59]. We found that overexpression or knockdown of prdm12b had no significant effect on PGC development in zebrafish (data not shown), suggesting PRDM family exert divergent roles in mammals and fish.

The members of small GTPase superfamily participate in almost every aspect of cell biology, which is comprised of five families conserved across eukaryotes: Ras, Rho, Rab, Arf, and Ran [60]. They alternate between GTP- and GDP-bound states, which act as molecular switches in regulation of polarity, cytoskeleton change, membrane invaginations in all eukaryotic cells $[44,60]$. The activity of RhoA/ROCK is essential for correct localization of germ plasm mRNAs at cleavage stage [28]. The Rac1 activation is essential for establishing the cell front and polarity of PGCs [61]. Cdc42 and ROCK regulate membrane invaginations, which is essential for motility of PGCs [62]. Inhibition of Rac/ROCK/Cdc42 activities by expression domain negative proteins significantly impairs PGC motility and leads to ectopic localization of PGCs. Rab proteins are the largest branch of Ras superfamily, which is critical in the regulation of vesicle formation and trafficking [44]. The Clathrinand Rab5-mediated endocytosis is required for activation of Rac, and the Rab5-to-Rac circuitry controls the morphology of motile PGCs in zebrafish [63]. Other members of Rab 
family participate in regulation of gametogenesis. Rab7 plays an important role in actin dynamics and mitochondria function in oocyte meiosis [64]. rab10 binds with the male germ cell-specific Rab GTPase-activating protein (MGCRABGAP) and the MGCRABGAP$\mathrm{RAB}$ complex localizes in the manchette structure of mature sperm, indicating a possible role in spermatogenesis [65]. However, whether rab10 participates in PGC development remains unclear. Herein, we found that disruption of rab10 balance through siRNA mediated reduction, overexpression of WT rab10, inactive or active rab10 mutants led to PGC mislocalization, demonstrating that proper expression of rab10, especially for the balance of rab10 GDP- and GTP-bound states, is critical for PGC migration (Figure 4). Because rab10 is negatively regulated by $m i R-202-5 p$, we used $m i R-202-5 p$ mimics to rescue PGC migratory defects in rab10 overexpressed embryos. However, overexpression of miR-202-5p partially rescued the migratory defects caused by rab10 overexpression (Figure 6), which might be because although miR-202-5p might rescue the expression level of rab10, the balance between rab10 GDP- and GTP-bound states remains in disorder. Taken together, miR-202-5p mediated balance of rab10 is important for PGC migration.

Finally, we observed that knockdown of rab10 could not significantly rescue PGC migration and even led to a severer migratory defect of PGCs in MmiR-202 embryos, no matter knockdown of $c d c 42 s e 1$ or not. There might be two possible explanations for why we failed to rescue PGC migration by knockdown of rab10 and cdc42se1 in MmiR-202 embryos. Firstly, injection of rab10 siRNA could rescue the expression level of rab10 but might cause a more significant disorder in the balance between rab10 GDP- and GTP- bound states in MmiR-202 embryos. Secondly, loss of miR-202-5p led to a complex dysregulation of downstream signaling networks besides rab10 and $c d c 42 s e 1$, such as the chemokine signaling. Chemokine-guided cell migration is essential for directing PGC migration towards the genital ridge [38]. Herein, we found that the ccl20a.3 chemokine was differentially expressed between WT and MmiR-202 PGCs, providing possible evidence suggesting that miR-202-5p might regulate PGC migratory behavior via chemokine signaling. However, which type of cell expressing ccl20a.3 chemokine receptor-ccr6 during early embryogenesis; whether and how ccr6 positive cells contribute to PGC migration towards the genital ridge needs to be further investigated. In summary, the present work provided transcriptional profiles of MmiR-202 PGCs, revealed the differentially expressed signaling pathways between WT and MmiR-202 PGCs, and identified two novel miR-202-5p target genes rab10 and $p r d m 12 b$. Loss- and gain-of-function demonstrated that rab10 is required for PGC migration. The present work provides important data for understanding the molecular mechanism underlying miR-202-5p regulation of zebrafish PGC.

\section{Materials and Methods}

\subsection{Ethics Statement}

All procedures with zebrafish were approved by the Ethics Committee of Sun Yat-sen University (31771587, 20 February 2017), and the methods were carried out in accordance with the approved guidelines.

\subsection{Zebrafish Strains and Cell Lines}

The AB line and transgenic line Tg kop: egfp-UTR-nos3 zebrafish were purchased from the China Zebrafish Resource Center. The maternal miR-202 mutant (MmiR-202) zebrafish has been generated in our previous study [15]. Fish were raised at $28^{\circ} \mathrm{C}$ with $10 \mathrm{~h}(\mathrm{~h})$ darkness and $14 \mathrm{~h}$ light in the zebrafish circulatory breeding system.

HEK $293 \mathrm{~T}$ cells were cultured at $37^{\circ} \mathrm{C}$ in Dulbecco's modified Eagle's medium (DMEM) supplied with 10\% FBS (Invitrogen, Carlsbad, CA, USA) under a humidified atmosphere of air containing $5 \% \mathrm{CO}_{2}$.

\subsection{Isolation of PGC and Transcriptome Analysis}

To label the PGCs with green fluorescence protein (GFP), 400pg gfp-nos $3^{\prime} u t r$ mRNA was injected into 1-cell WT and MmiR-202 embryos. At $24 \mathrm{hpf}$, the embryos were digested 
to single-cell suspension by trypsin according to the zebrafish book (http:/ / zfin.org/zf info/zfbook/zfbk.html, 4th version, accessed date: 7 October 2021). A total of 900 WT and $900 \mathrm{MmiR}$-202 PGCs were collected by FACS based on the GFP signal. The isolated PGCs were equally divided into three technical replicates of WT PGCs and MmiR-202 PGCs groups for Illumina sequencing on the MGIseq2000 platform (Anoroad genome, Beijing, China).

\subsection{Transcriptome Sequencing and Bioinformatic Analysis}

After sequencing, clean reads were obtained with Perl scripts to clear raw read containing more than 5 adapter-polluted bases, the number of $\mathrm{N}$ bases accounting for more than $5 \%$, as well as the phred quality value less than 19 accounting for more than $15 \%$. Clean reads were mapped to the reference genome and annotation file downloaded from Ensembl (Danio rerio GRCz10.89.gtf) with HISAT2 [66]. Read Count for each gene in each sample is counted by HTSeq and gene expression level was calculated using FPKM (Fragments Per Kilobase Millon Mapped Reads). To yield reliable results, genes with FPKM $\geq 1$ in at least three samples were taken for differential expression analysis between WT and MmiR-202 PGCs with DEGseq with BH method (false discovery rate correction with BenjaminiHochberg), and genes with $\mathrm{q} \leq 0.05$ and $\mid \log 2$ ratio $\mid \geq 1$ were identified as differentially expressed genes. The biological signaling pathway of DEGs was analyzed by functional enrichment in GO terms (Gene Ontology, http:/ / geneontology.org/, 1 January 2021) and KEGG pathways (Kyoto Encyclopedia of Genes and Genomes, http:/ / www.kegg.jp/, Release 97.0, 1 January 2021). GO terms with $\mathrm{q}<0.05$ were considered significantly enriched.

\subsection{Embryo Collection and RNA Isolation}

For RNA isolation, WT embryos, embryos injected control or miR-202-5p mimics, control siRNA or different dosages (50/150/300 pg each embryo) of rab10 siRNAs, as well as embryos injected with $g f p$ mRNA or different dosages (50/100/200 pg each embryo) of rab10 mRNA were collected at $24 \mathrm{hpf}$, frozen in liquid nitrogen and stored in $-80^{\circ} \mathrm{C}$. The collected embryos were homogenized in $1 \mathrm{~mL}$ of trizol reagent (Invitrogen, Carlsbad, CA, USA), and total RNA was extracted according to the manufacturer's instructions.

\subsection{Reverse Transcription and $q P C R$ Analysis}

To examine the expression levels of predicted DEGs between WT and MmiR-202 PGCs, the RNA of collected PGCs was reverse-transcribed with single-cell sequence-specific amplification kit to establish first the cDNA library (Vazyme, Nanjing, China). The extracted RNA of other embryos was reverse-transcribed into single-strand cDNA with primescript ${ }^{\mathrm{TM}}$ first-strand cDNA synthesis kit (Takara, Kyoto, Japan). To avoid the error caused by single reference genes in single-cell PCR validation, we used three common reference genes including ef1a, $\beta$-actin and rpl13a to normalize gene expression levels using $2^{-\Delta \Delta C t}$ method in every PCR examination. The results were representative of more than three independent experiments in triplicate. Each independent experiment was performed in triplicate.

qPCR analysis was performed on the LightCycler480 II (Roche, Basel, Switzerland) with the chamQ universal SYBR qPCR master mix (Vazyme, Nanjing, China) as previously described [67]. Primer sequences were listed in Table A1.

\subsection{Plasmid Construction and mRNA Transcription}

For luciferase or RFP reporters, the $3^{\prime} \mathrm{UTR}$ of rab10 (ENSDARG00000046106) or prdm12b (ENSDARG00000007430) were cloned and fused to the ORF of luciferase and RFP in the psiCHECK2 and pCS2 plus (pCS2+) vectors, respectively.

For universal rab10 overexpression, full ORF and 3'UTR of rab10 was inserted to pCS2+ vector. To specifically overexpress rab10 in PGCs, the ORF of rab10 and $g f p$ as well as the $3^{\prime} \mathrm{UTR}$ of nanos3 were inserted to pCS2+ vector to generate the $p C S 2-r a b 10-g f p$-nos $3^{\prime} u$ tr plasmid. 
All the point mutants including miR-202-5p binding sites within the $3^{\prime}$ UTRs of rab10 or $\operatorname{prdm} 12 b$, and the inactive or active rab10 mutants were constructed with hieff mut ${ }^{\mathrm{tm}}$ multi-sitedirected mutagenesis kit (Yeasen, Shanghai, China) as previously described [15,45].

For mRNA synthesis, recombinant pCS2+ plasmids were linearized with NotI and transcribed using SP6 mMESSAGE mMACHINE Kit (Invitrogen, Carlsbad, CA, USA) according to the manufacturer's instructions.

\subsection{Micro-Injection}

To knockdown rab10, three dosages (50/150/300 pg each embryo) of rab10 siRNA (GCCAACATCAACATCGAGA) or 200 pg control siRNA (RiboBio, Guangzhou, China) was respectively injected into 1-cell WT embryos to knockdown endogenous rab10, and the embryos were collected for qPCR analysis of rab10 expression. Subsequently, the rab10 siRNA was injected into 1-cell embryos of kop: egfp-UTR-nos3 line.

To overexpress rab10, different dosages (50/100/200 pg each embryo) of rab10, rab10T23N and rab10Q68L mRNA were respectively injected into 1-cell embryos of Tg kop: egfp-UTR-nos3 line.

To rescue PGC migration in embryos injected rab10 mRNA or rab10 siRNA, 50 pg rab10 siRNA or 100 pg rab10 mRNA were co-injected into 1-cell embryos of Tg kop: egfp-UTR-nos3 line, and PGC migration was observed at $24 \mathrm{hpf}$. Furthermore, $300 \mathrm{pg}$ miR-202-5p mimics were co-injected to rescue PGC migration in rab10 mRNA injected embryos.

To rescue migratory defects in MmiR-202 PGCs, embryos were injected with different dosages (50/150/300 pg each embryo) of rab10 siRNA or $4000 \mathrm{pg} c d c 42 s e 1$ morpholino, respectively.

To confirm rab10 or prdm12b were miR-202-5p target genes, 200 pg rfp-prdm12b-3'utr-wt, rfp-prdm12b-3'utr-mut, rfp-rab10-3'utr-wt or rfp-rab10-3'utr-mut mRNA was co-injected with control or miR-202-5p mimics. At $24 \mathrm{hpf}$, representative images of corresponding embryos were captured with the stereo fluorescence microscope (Nikon, SMZ800N, Japan). And the average signal intensity of RFP was measured by Image J (version 1.51).

All the PGC migration was examined at $24 \mathrm{hpf}$ with the stereo fluorescence microscope (SMZ800N, Nikon, Kyoto, Japan). All experiments were performed in more than three independent experiments in triplicate. Each independent experiment was performed in triplicate.

\subsection{Dual Luciferase Reporter Assay}

At $70-80 \%$ confluence, HEK293T cells seeded in 24-well plates were transiently co-transfected 10 ng psiCHECK2-3'UTR-prdm12b-WT (psiCHECK2-3'UTR-rab10-WT) or psiCHECK2-3'UTR-prdm12b-seed-Mut (psiCHECK2-3'UTR-rab10-seed-Mut) plasmids and 100nM control or miR-202-5p mimics with Lipofectamine 8000 (Beyotime, Shanghai, China). The cells were lysed $24 \mathrm{~h}$ post-transfection, and the luciferase activity was detected by the dual-luciferase reporter analysis system (Promega, Madison, WI, USA). The results were representative of more than three independent experiments, each performed in triplicate. Each independent experiment was performed in triplicate.

\subsection{PGC Phenotype Observation}

At $24 \mathrm{hpf}$, PGCs of different groups of embryos were observed with the stereoscopic fluorescence microscope. The delineation of normal and mislocalized phenotype were distinguished as following: embryos with less than 3 ectopic PGCs were regarded as normal, whereas embryos with more than 3 ectopic PGCs were regarded as mislocalization. At least four repeated groups of embryos (30-50 embryos in each group) were observed.

\subsection{Statistics Analysis}

The statistics were calculated and analyzed with SPSS version 20. The qPCR results were analyzed by Student's $t$-test, and the phenotypes in different experimental groups were analyzed by one-way ANOVA. $p<0.5$ was considered a statistically significant difference. 
Author Contributions: W.L. (Wei Liu) and M.Y. designed and supervised the experiments, as well as edited the manuscript. C.M. and W.L. (Wenjing Li) carried out the experiments and drafted the manuscript. C.M. performed the bioinformatic analyses. W.L. (Wenjing Li) and K.J. performed the statistical analyses. All authors have read and agreed to the published version of the manuscript.

Funding: This work was supported by National Natural Science Foundation of China (31771587, 31970535), Guangdong Basic and Applied Basic Research Foundation (2020A1515010358).

Institutional Review Board Statement: All experimental procedures with zebrafish were approved by the Ethics Committee of Sun Yat-sen University (No. 31771587, 20 February 2017), and the methods were in accordance with the approved guidelines.

Informed Consent Statement: Written informed consent, including consent for publication, was obtained from the patient.

Data Availability Statement: All the Illumina sequencing reads (SRA: PRJNA768286) have been deposited in the NCBI.

Conflicts of Interest: The authors have declared no conflict of interest. The funders had no role in the design of the study; in the collection, analyses, or interpretation of data; in the writing of the manuscript, or in the decision to publish the results.

\begin{tabular}{ll}
\multicolumn{2}{l}{ Abbreviations } \\
3'UTR & 3'untranslated region $^{\prime}$ differentially expressed genes \\
DEGs & Dulbecco's modified Eagle's medium \\
DMEM & $\begin{array}{l}\text { extracellular matrix } \\
\text { ECM }\end{array}$ \\
FACS & fluorescence activated cell sorting \\
FPKM & Fragments Per Kilobase Millon Mapped Reads \\
GFP & green fluorescence protein \\
GO & Gene Ontology \\
KEGG & Kyoto Encyclopedia of Genes and Genomes \\
miRNAs & MicroRNAs \\
Mlck & myosin light chain kinase \\
MmiR-202 & maternal miR-202 mutant \\
ORF & open reading frame \\
PGCs & Primordial germ cells \\
PRDM & PR domain containing \\
qPCR & Quantitative polymerase chain reaction \\
RFP & red fluorescent protein \\
WT & wild type
\end{tabular}

Appendix A

Table A1. Sequences of primer used in this paper.

\begin{tabular}{|c|c|c|}
\hline Description & Primer Name & Primer Sequence $\left(5^{\prime}-3^{\prime}\right)$ \\
\hline \multirow[t]{7}{*}{ psiCHECK2 } & rab10-3'UTR-XhoI-F & CCGCTCGAGCACACACGCACACACAATCTGTTCTACT \\
\hline & rab10-3'UTR-NotI-R & ATAAGAATGCGGCCGCCGTGAGTGTGAGAAACGTTAGAGATG \\
\hline & rab10-3'UTR-seed Mut-R & GTTAGAGATGTGTTTTACAGAGAATCTCGCGAGAAGG \\
\hline & prdm12b-3'UTR-XhoI-F & CCGCTCGAG ACCACACCACGTTATTTGCT \\
\hline & prdm12b-3'UTR-NotI-R & ATAAGAATGCGGCCGCAGGTGAGCTAAATTGGCCG \\
\hline & prdm12b-3'UTR-seed Mut-F & GGAATGTACGCGAGATTTGAACTTTTACG \\
\hline & prdm12b-3'UTR-seed Mut-R & GTTCAAATCTCGCGTACATTCCTTTAC \\
\hline
\end{tabular}


Table A1. Cont.

\begin{tabular}{|c|c|c|}
\hline Description & Primer Name & Primer Sequence $\left(5^{\prime}-3^{\prime}\right)$ \\
\hline \multirow{7}{*}{$\begin{array}{l}\text { pCS2 + mRNA } \\
\text { synthesis }\end{array}$} & rab10-Bamh I-F & ACGGGATCCAGCTCAGATGGCGAAGAAGACCTATGATC \\
\hline & rab10-Age I-R & ACTACCGGTGGACTGCAGCACTTGGTCTTCCAGCCT \\
\hline & rab10-XhoI-R & CCGCTCGAGCGTGAGTGTGAGAAACGTTAGAGATG \\
\hline & rab10T23N-F & TGATTGGCGATTCTGGGGTGGGAAAGAACTGCGTGCTGTT \\
\hline & rab10T23N-R & TCATCGGAGAATCGGAACAGCACGCAGTTCTTTCCCACCC \\
\hline & rab10Q68L-F & GCTACAGATATGGGATACAGCGGGGCTGGAACGGTTTCAC \\
\hline & rab10Q68L-R & AGGTAGTGATGGTGTGAAACCGTTCCAGCCCCGCTGTATC \\
\hline \multirow{30}{*}{ qRT-PCR } & efla-F & GGCTGACTGTGCTGTGCTGATTG \\
\hline & ef $1 a-\mathrm{R}$ & CTTGTCGGTGGGACGGCTAGG \\
\hline & actin-F & CGAGCTGTCTTCCCATCCA \\
\hline & actin-R & TCACCAACGTAGCTGTCTTTCTG \\
\hline & rpl13a-F & TCTGGAGGACTGTAAGAGGTATGC \\
\hline & rpl13a-R & AGACGCACAATCTTGAGAGCAG \\
\hline & rab10-RT-F & CGCСТTCAACACCACСТTTAT \\
\hline & rab10-RT-R & GCATССТСТССАСАТССТСАТ \\
\hline & prdm12b-RT-F & TCGCAGCTGGATGACTTACA \\
\hline & prdm12b-RT-R & TCCCATACCACACAAGCAGT \\
\hline & anxa1c-RT-F & ACACCTTGAAGACTGCCTGA \\
\hline & anxa1c-RT-R & CCGAACGGCTCACAATGATT \\
\hline & cldne-RT-F & GGGAAATGCACCAACTTCGT \\
\hline & cldne-RT-R & CTCTGATGATGGTGTTGGCG \\
\hline & $m c f 2 a-\mathrm{RT}-\mathrm{R}$ & GCAGCGCTATTGAGTTCCTC \\
\hline & $m c f 2 a-\mathrm{RT}-\mathrm{F}$ & AGTCCTGTGTGATGTCCCAG \\
\hline & megf6a-RT-F & CAGGGCAGGTTACAGACTCA \\
\hline & $m e g f 6 a-R T-R$ & GTCTGTCCTCACCAAGTCGA \\
\hline & $m y l 7-R T-F$ & TGCACAACTAGGGAAGCTGA \\
\hline & myl7-RT-R & GGTCTGTGCCATTGAGCTTC \\
\hline & rab36-RT-F & GCCGTAAAGATTGCAGCAGA \\
\hline & rab36-RT-R & ACTGCCATCTCCGATCTGAG \\
\hline & $h m g x b 4 a-\mathrm{RT}-\mathrm{F}$ & TCGTCTCTGGGCATGTCTTT \\
\hline & hmgxb4a-RT-R & CTGTCTCCTGAAGTCGGTGT \\
\hline & synpo21b-RT-F & СААССТАСТССАGСАССТСА \\
\hline & synpo21b-RT-R & TGTGGAGGACTGAATGGCAT \\
\hline & dnd-RT-F & GGCTAAGAAAGTGCTCGTGG \\
\hline & $d n d-\mathrm{RT}-\mathrm{R}$ & GCTGGGACGTCATAATGCAG \\
\hline & gra-RT-F & CCTTAAAAGCACCGAGACCC \\
\hline & gra-RT-R & AAGTATCTGGGCAGGTCACT \\
\hline
\end{tabular}

\section{References}

1. Marlow, F. Primordial Germ Cell Specification and Migration. F1000Research 2015, 4. F1000 Faculty Rev-1462. [CrossRef] [PubMed]

2. Hayashi, K.; de Sousa Lopes, S.M.C.; Surani, M.A. Germ cell specification in mice. Science 2007, 316, 394-396. [CrossRef] [PubMed]

3. Aalto, A.; Olguin-Olguin, A.; Raz, E. Zebrafish Primordial Germ Cell Migration. Front. Cell Dev. Biol. 2021, 9, 684460. [CrossRef] [PubMed]

4. Barton, L.J.; LeBlanc, M.G.; Lehmann, R. Finding their way: Themes in germ cell migration. Curr. Opin. Cell Biol. 2016, 42, 128-137. [CrossRef] [PubMed]

5. Paksa, A.; Raz, E. Zebrafish germ cells: Motility and guided migration. Curr. Opin. Cell Biol. 2015, 36, 80-85. [CrossRef] [PubMed]

6. Richardson, B.E.; Lehmann, R. Mechanisms guiding primordial germ cell migration: Strategies from different organisms. Nat. Rev. Mol. Cell Biol. 2010, 11, 37-49. [CrossRef] [PubMed]

7. Blaser, H.; Reichman-Fried, M.; Castanon, I.; Dumstrei, K.; Florence, L.M.; Kawakami, K.; Solnica-Krezel, L.; Heisenberg, C.-P.; Raz, E. Migration of Zebrafish Primordial Germ Cells: A Role for Myosin Contraction and Cytoplasmic Flow. Dev. Cell 2012, 11, 613-627. [CrossRef]

8. Weidinger, G.; Stebler, J.; Slanchev, K.; Dumstrei, K.; Wise, C.; Lovell-Badge, R.; Thisse, C.; Thisse, B.; Raz, E. dead end, a novel vertebrate germ plasm component, is required for zebrafish primordial germ cell migration and survival. Curr. Biol. 2003, 13, 1429-1434. [CrossRef] 
9. Koprunner, M.; Thisse, C.; Thisse, B.; Raz, E. A zebrafish nanos-related gene is essential for the development of primordial germ cells. Genes Dev. 2001, 15, 2877-2885. [PubMed]

10. Yoon, C.; Kawakami, K.; Hopkins, N. Zebrafish vasa homologue RNA is localized to the cleavage planes of 2- and 4-cell-stage embryos and is expressed in the primordial germ cells. Development 1997, 124, 3157-3165. [CrossRef]

11. McHugh, C.A.; Chen, C.-K.; Chow, A.; Surka, C.F.; Tran, C.; McDonel, P.; Pandya-Jones, A.; Blanco, M.; Burghard, C.; Moradian, A.; et al. The Xist lncRNA interacts directly with SHARP to silence transcription through HDAC3. Nature 2015, 521, 232-236. [CrossRef]

12. Kloc, M.; Spohr, G.; Etkin, L. Translocation of repetitive RNA sequences with the germ plasm in Xenopus oocytes. Science 1993, 262, 1712-1714. [CrossRef] [PubMed]

13. Martinho, R.G.; Kunwar, P.S.; Casanova, J.; Lehmann, R. A noncoding RNA is required for the repression of RNApolII-dependent transcription in primordial germ cells. Curr. Biol. 2004, 14, 159-165. [CrossRef] [PubMed]

14. Houwing, S.; Kamminga, L.M.; Berezikov, E.; Cronembold, D.; Girard, A.; van den Elst, H.; Filippov, D.V.; Blaser, H.; Raz, E.; Moens, C.B.; et al. A role for Piwi and piRNAs in germ cell maintenance and transposon silencing in Zebrafish. Cell 2007, 129, 69-82. [CrossRef]

15. Jin, Y.; Liu, W.; Xiang, Y.; Zhang, W.; Zhang, H.; Jia, K.; Yi, M. Maternal miR-202-5p is required for zebrafish primordial germ cell migration by protecting small GTPase Cdc42. J. Mol. Cell Biol. 2020, 12, 530-542. [CrossRef]

16. Zhang, J.; Liu, W.; Jin, Y.; Jia, P.; Jia, K.; Yi, M. MiR-202-5p is a novel germ plasm-specific microRNA in zebrafish. Sci Rep. 2017, 7, 7055. [CrossRef]

17. Kugler, J.M.; Chen, Y.W.; Weng, R.; Cohen, S.M. Maternal loss of miRNAs leads to increased variance in primordial germ cell numbers in Drosophila melanogaster. G3 2013, 3, 1573-1576. [CrossRef]

18. Cinalli, R.M.; Rangan, P.; Lehmann, R. Germ cells are forever. Cell 2008, 132, 559-562. [CrossRef] [PubMed]

19. Wylie, C. Germ cells. Cell 1999, 96, 165-174. [CrossRef]

20. Magnúsdóttir, E.; Surani, M.A. How to make a primordial germ cell. Development 2014, 141, 245-252. [CrossRef] [PubMed]

21. Paluch, E.K.; Raz, E. The role and regulation of blebs in cell migration. Curr. Opin. Cell Biol. 2013, 25, 582-590. [CrossRef]

22. Hartwig, J.; Tarbashevich, K.; Seggewiss, J.; Stehling, M.; Bandemer, J.; Grimaldi, C.; Paksa, A.; Gross-Thebing, T.; Meyen, D.; Raz, E. Temporal control over the initiation of cell motility by a regulator of G-protein signaling. Proc. Natl. Acad. Sci. USA 2014, 111, 11389-11394. [CrossRef] [PubMed]

23. Goudarzi, M.; Banisch, T.U.; Mobin, M.B.; Maghelli, N.; Tarbashevich, K.; Strate, I.; van den Berg, J.; Blaser, H.; Bandemer, S.; Paluch, E.; et al. Identification and regulation of a molecular module for bleb-based cell motility. Dev. Cell 2012, 23, 210-218. [CrossRef] [PubMed]

24. Doitsidou, M.; Reichman-Fried, M.; Stebler, J.; Koprunner, M.; Dorries, J.; Meyer, D.; Esguerra, C.V.; Leung, T.; Raz, E. Guidance of primordial germ cell migration by the chemokine SDF-1. Cell 2002, 111, 647-659. [CrossRef]

25. Tarbashevich, K.; Reichman-Fried, M.; Grimaldi, C.; Raz, E. Chemokine-Dependent pH Elevation at the Cell Front Sustains Polarity in Directionally Migrating Zebrafish Germ Cells. Curr. Biol. 2015, 25, 1096-1103. [CrossRef]

26. Grimaldi, C.; Schumacher, I.; Boquet-Pujadas, A.; Tarbashevich, K.; Vos, B.E.; Bandemer, J.; Schick, J.; Aalto, A.; Olivo-Marin, J.C.; Betz, T.; et al. E-cadherin focuses protrusion formation at the front of migrating cells by impeding actin flow. Nat. Commun. 2020, 11, 5397. [CrossRef]

27. Goudarzi, M.; Tarbashevich, K.; Mildner, K.; Begemann, I.; Garcia, J.; Paksa, A.; Reichman-Fried, M.; Mahabaleshwar, H.; Blaser, H.; Hartwig, J.; et al. Bleb expansion in migrating cells depends on supply of membrane from cell surface invaginations. Dev. Cell 2017, 43, 577-587. [CrossRef] [PubMed]

28. Miranda-Rodriguez, J.R.; Salas-Vidal, E.; Lomeli, H.; Zurita, M.; Schnabel, D. RhoA/ROCK pathway activity is essential for the correct localization of the germ plasm mRNAs in zebrafish embryos. Dev. Biol. 2017, 421, 27-42. [CrossRef] [PubMed]

29. Bartel, D.P. MicroRNAs: Target recognition and regulatory functions. Cell 2009, 136, 215-233. [CrossRef] [PubMed]

30. Gebert, L.F.R.; MacRae, I.J. Regulation of microRNA function in animals. Nat. Rev. Mol. Cell Biol. 2019, 20, 21-37. [CrossRef] [PubMed]

31. Batool, A.; Karimi, N.; Wu, X.N.; Chen, S.R.; Liu, Y.X. Testicular germ cell tumor: A comprehensive review. Cell Mol. Life Sci 2019, 76, 1713-1727. [CrossRef] [PubMed]

32. Treiber, T.; Treiber, N.; Meister, G. Regulation of microRNA biogenesis and its crosstalk with other cellular pathways. Nat. Rev. Mol. Cell Biol. 2019, 20, 5-20. [CrossRef] [PubMed]

33. Matzuk, M.M. LIN28 lets BLIMP1 Take the Right Course. Dev. Cell 2009, 17, 160-161. [CrossRef]

34. Viswanathan, S.R.; Daley, G.Q.; Gregory, R.I. Selective blockade of microRNA processing by Lin28. Science 2008, 320, 97-100. [CrossRef] [PubMed]

35. West, J.A.; Viswanathan, S.R.; Yabuuchi, A.; Cunniff, K.; Takeuchi, A.; Park, I.H.; Sero, J.E.; Zhu, H.; Perez-Atayde, A.; Frazier, A.L.; et al. A role for Lin28 in primordial germ-cell development and germ-cell malignancy. Nature 2009, 460, 909913. [CrossRef]

36. Melton, C.; Judson, R.L.; Blelloch, R. Opposing microRNA families regulate self-renewal in mouse embryonic stem cells. Nature 2010, 463, 621-626. [CrossRef]

37. Giraldez, A.J.; Mishima, Y.; Rihel, J.; Grocock, R.J.; Van Dongen, S.; Inoue, K.; Enright, A.J.; Schier, A.F. Zebrafish MiR-430 promotes deadenylation and clearance of maternal mRNAs. Science 2006, 312, 75-79. [CrossRef] 
38. Staton, A.A.; Knaut, H.; Giraldez, A.J. miRNA regulation of Sdf1 chemokine signaling provides genetic robustness to germ cell migration. Nat. Genet. 2011, 43, 204-211. [CrossRef] [PubMed]

39. Jia, K.T.; Zhang, J.; Jia, P.; Zeng, L.; Jin, Y.; Yuan, Y.; Chen, J.; Hong, Y.; Yi, M. Identification of MicroRNAs in Zebrafish Spermatozoa. Zebrafish 2015, 12, 387-397. [CrossRef] [PubMed]

40. Bizuayehu, T.T.; Babiak, I. Heterogenic Origin of Micro RNAs in Atlantic Salmon (Salmo salar) Seminal Plasma. Int. J. Mol. Sci 2020, 21, 2723. [CrossRef] [PubMed]

41. Gay, S.; Bugeon, J.; Bouchareb, A.; Henry, L.; Delahaye, C.; Legeai, F.; Montfort, J.; Le Cam, A.; Siegel, A.; Bobe, J.; et al. MiR-202 controls female fecundity by regulating medaka oogenesis. PLoS Genet. 2018, 14, e1007593. [CrossRef]

42. Bendel-Stenzel, M.R.; Gomperts, M.; Anderson, R.; Heasman, J.; Wylie, C. The role of cadherins during primordial germ cell migration and early gonad formation in the mouse. Mech Dev. 2000, 91, 143-152. [CrossRef]

43. Liu, W.; Jin, Y.; Zhang, W.; Xiang, Y.; Jia, P.; Yi, M.; Jia, K. MiR-202-5p Inhibits RIG-I-Dependent Innate Immune Responses to RGNNV Infection by Targeting TRIM25 to Mediate RIG-I Ubiquitination. Viruses 2020, 12, 261. [CrossRef]

44. Li, G.; Marlin, M.C. Rab family of GTPases. Methods Mol. Biol. 2015, 1298, 1-15. [PubMed]

45. Schuck, S.; Gerl, M.J.; Ang, A.; Manninen, A.; Keller, P.; Mellman, I.; Simons, K. Rab10 is involved in basolateral transport in polarized Madin-Darby canine kidney cells. Traffic 2007, 8, 47-60. [CrossRef] [PubMed]

46. Dabaja, A.A.; Mielnik, A.; Robinson, B.D.; Wosnitzer, M.S.; Schlegel, P.N.; Paduch, D.A. Possible germ cell-Sertoli cell interactions are critical for establishing appropriate expression levels for the Sertoli cell-specific MicroRNA, miR-202-5p, in human testis. Basic Clin. Androl. 2015, 25, 2. [CrossRef] [PubMed]

47. Xu, L.; Guo, Q.; Chang, G.; Qiu, L.; Liu, X.; Bi, Y.; Zhang, Y.; Wang, H.; Lu, W.; Ren, L.; et al. Discovery of microRNAs during early spermatogenesis in chicken. PLoS ONE 2017, 12, e0177098. [CrossRef]

48. Chen, J.; Sun, Q.; Liu, G.Z.; Zhang, F.; Liu, C.Y.; Yuan, Q.M.; Di, X.S.; Long, S.W.; Jia, Y.S.; Wang, Y.J. Effect of miR-202-5p-mediated ATG7 on autophagy and apoptosis of degenerative nucleus pulposus cells. Eur. Rev. Med. Pharmacol. 2020, 24, 517-525.

49. Yu, H.Y.; Pan, S.S. MiR-202-5p suppressed cell proliferation, migration and invasion in ovarian cancer via regulating HOXB2. Eur. Rev. Med. Pharmacol. 2020, 24, 2256-2263.

50. Li, C.; Ma, D.; Yang, J.; Lin, X.; Chen, B. miR-202-5p inhibits the migration and invasion of osteosarcoma cells by targeting ROCK1. Oncol. Lett. 2018, 16, 829-834. [CrossRef] [PubMed]

51. Liu, T.; Guo, J.; Zhang, X. MiR-202-5p/PTEN mediates doxorubicin-resistance of breast cancer cells via PI3K/Akt signaling pathway. Cancer Biol. Ther. 2019, 20, 989-998. [CrossRef]

52. Wainwright, E.N.; Jorgensen, J.S.; Kim, Y.; Truong, V.; Bagheri-Fam, S.; Davidson, T.; Svingen, T.; Fernandez-Valverde, S.L.; McClelland, K.S.; Taft, R.J. SOX9 regulates microRNA miR-202-5p/3p expression during mouse testis differentiation. Biol. Reprod. 2013, 89, 34. [CrossRef] [PubMed]

53. Armisen, J.; Gilchrist, M.J.; Wilczynska, A.; Standart, N.; Miska, E.A. Abundant and dynamically expressed miRNAs, piRNAs, and other small RNAs in the vertebrate Xenopus tropicalis. Genome Res. 2009, 19, 1766-1775. [CrossRef]

54. Blaser, H.; Eisenbeiss, S.; Neumann, M.; Reichman-Fried, M.; Thisse, B.; Thisse, C.; Raz, E. Transition from non-motile behaviour to directed migration during early PGC development in zebrafish. J. Cell Sci. 2005, 118 Pt 17, 4027-4038. [CrossRef] [PubMed]

55. Weidinger, G.; Wolke, U.; Koprunner, M.; Klinger, M.; Raz, E. Identification of tissues and patterning events required for distinct steps in early migration of zebrafish primordial germ cells. Development 1999, 126, 5295-5307. [CrossRef] [PubMed]

56. Mishima, Y.; Giraldez, A.J.; Takeda, Y.; Fujiwara, T.; Sakamoto, H.; Schier, A.F.; Inoue, K. Differential regulation of germline mRNAs in soma and germ cells by zebrafish miR-430. Curr. Biol. 2006, 16, 2135-2142. [CrossRef] [PubMed]

57. Ohinata, Y.; Payer, B.; O'Carroll, D.; Ancelin, K.; Ono, Y.; Sano, M.; Barton, S.C.; Obukhanych, T.; Nussenzweig, M.; Tarakhovsky, A.; et al. Blimp1 is a critical determinant of the germ cell lineage in mice. Nature 2005, 436, 207-213. [CrossRef] [PubMed]

58. Sybirna, A.; Tang, W.W.C.; Pierson Smela, M.; Dietmann, S.; Gruhn, W.H.; Brosh, R.; Surani, M.A. A critical role of PRDM14 in human primordial germ cell fate revealed by inducible degrons. Nat. Commun. 2020, 11, 1282. [CrossRef] [PubMed]

59. Ding, H.L.; Clouthier, D.E.; Artinger, K.B. Redundant roles of PRDM family members in zebrafish craniofacial development. Dev. Dyn. 2013, 242, 67-79. [CrossRef]

60. Reiner, D.J.; Lundquist, E.A. Small GTPases. In The Online Review of C. elegans Biology; WormBook: Pasadena, CA, USA, 2018; pp. 1-65.

61. Olguin-Olguin, A.; Aalto, A.; Maugis, B.; Boquet-Pujadas, A.; Hoffmann, D.; Ermlich, L.; Betz, T.; Gov, N.S.; Reichman-Fried, M.; Raz, E. Chemokine-biased robust self-organizing polarization of migrating cells in vivo. Proc. Natl. Acad. Sci. USA 2021, 118, e2018480118. [CrossRef]

62. Lui, W.Y.; Lee, W.M.; Cheng, C.Y. Sertoli-germ cell adherens junction dynamics in the testis are regulated by RhoB GTPase via the ROCK/LIMK signaling pathway. Biol. Reprod. 2003, 68, 2189-2206. [CrossRef]

63. Palamidessi, A.; Frittoli, E.; Garré, M.; Faretta, M.; Mione, M.; Testa, I.; Diaspro, A.; Lanzetti, L.; Scita, G.; Di Fiore, P.P. Endocytic trafficking of Rac is required for the spatial restriction of signaling in cell migration. Cell 2008, 134, 135-147. [CrossRef] [PubMed]

64. Pan, Z.N.; Pan, M.H.; Sun, M.H.; Li, X.H.; Zhang, Y.; Sun, S.C. RAB7 GTPase regulates actin dynamics for DRP1-mediated mitochondria function and spindle migration in mouse oocyte meiosis. FASEB J. 2020, 34, 9615-9627. [CrossRef] [PubMed]

65. Lin, Y.-H.; Ke, C.-C.; Wang, Y.-Y.; Chen, M.-F.; Chen, T.-M.; Ku, W.-C.; Chiang, H.-S.; Yeh, C.-H. RAB10 Interacts with the Male Germ Cell-Specific GTPase-Activating Protein during Mammalian Spermiogenesis. Int. J. Mol. Sci 2017, 18, 97. [CrossRef] [PubMed] 
66. Kim, D.; Langmead, B.; Salzberg, S.L. HISAT: A fast spliced aligner with low memory requirements. Nat. Methods 2015, 12, 357-360. [CrossRef] [PubMed]

67. Liu, W.; Zhang, H.; Xiang, Y.; Jia, K.; Luo, M.; Yi, M. A novel germline and somatic cell expression of two sexual differentiation genes, Dmrt1 and Foxl2 in marbled goby (Oxyeleotris marmorata). Aquaculture 2020, 516, 734619. [CrossRef] 